Professor and Mrs. H. M. Hall have given us of the Yosemite.

We have had a feeling that our manuals must cover vast sections of the country, many hundreds of thousands of square miles; that they must be complete, accounting for everything ever mentioned. As a result much is found in our volumes that describes things that do not exist, are very rare or have only historical interest for the technically trained. I am pleading for those who want to know the plants that relate themselves to their professional work, to their mental life or to their recreations. Please note I said know the plants, not know plant names. No one wishes to know names apart from the plants in which he is interested. Knowing the plant is first, and then a name becomes indispensable.

And why not a name instead of a manufactured phrase palmed off as an English name? In what respect is "purple-stemmed swamp beggar ticks" better than the name? We use geranium, magnolia, forsythia, and scores of others. Why not phlox, mertensia, chrysopsis or practically any other generic name? It is true this only designates the genus, but this is all that many who are intensely interested in the plants care to know, as exemplified by our use of the words clematis, chrysanthemum, lupines and roses. Those who wish to designate the species can do so with more celerity and certainty by saying Phlox glabrata than by smooth-leaved sweet william. In my recent "Spring Flora" I proposed this use of the generic name seriously and I wish to assert that I have seen no reason for changing my opinion.

In closing let me express the belief that we are on the eve of a new era. Already the pendulum is swinging back. The dismemberment of genera and the multiplications of species proceed more cautiously. New species will continue to be found even in this country (hundreds of them). These ought to be and will be published. So long as work is done errors must occur, but the percentage of error, let us hope, will be greatly reduced, while the disturbing effect will be minimized by more and more of constructive work of the compendium type.

AVEN NeLsoN

UNIVERSITY OF WYOMING, LARAMIE, Wro.

\section{ON AN EXPERIMENTAL DETERMINATION OF THE EARTH'S ELASTIC PROPERTIES}

IT is well known that the ocean tides are caused by the differences in the attraction of the sun and moon for the surface and center of the earth. These differential forces are very small compared with the attraction of the earth for bodies on its surface; in round numbers the joint tidal force of the sun and moon on a body at the earth's surface under the most favorable circumstances amounts to only about $1 / 10,000,000$ of the weight of the body. This force would deflect the bob of a plumb line 10 feet long from its normal position only about $1 / 100,000$ of an inch. This deviation corresponds to an angle of only $.02^{\prime \prime}$, or the angle which the head of a pin would subtend at a distance of 10 miles.

If the earth were a perfectly fluid mass, $i$. e., if it offered no resistance, either elastic or viscous, to changes of shape, the surface would be tilted by the tidal forces through this same angle, and the new horizontal would be perpendicular to the new vertical. There would therefore be no change of the plumb-line relative to the earth's surface, and we could not detect the so-called "deflection of the vertical."

If the earth were perfectly rigid the plumb line would move back and forth, as the positions of the sun and moon vary, by an amount which can be calculated with an accuracy which is limited only by our knowledge of the masses and relative positions of the sun, earth and moon. As a matter of fact, the earth is partially and not entirely rigid, and therefore the excursions of the plumb line are a certain 
fractional part of the full computed value. After this fraction has been found by experiment, it is possible to compute the rigidity of the earth.

In 1879 George and Horace Darwin, at Cambridge, England, attempted to measure the rigidity of the earth. They used a heavy pendulum whose motions were greatly magnified by suspending a small mirror by two fibers very close together, one of which was fastened to the pendulum bob, and the other to a rigid support. However, even with this extremely sensitive apparatus they were unable to separate any movements due to the moon's attraction from the multitude of disturbing displacements caused by changes of temperature, earth tremors, etc.

Of these disturbing elements, a very serious one is the distortion of the land caused by the immense weight of water periodically thrown upon the coasts in the ocean tides. As late as $1898 \mathrm{Sir}$ George Darwin said that he doubted if it would ever be possible to isolate the effects of the tidal forces from the multitudinous disturbances of a more or less accidental character, although he recognized a possibility in the work of Paschwitz and his successor Ehlert, at Strassburg. They had already secured encouraging results by the use of the horizontal pendulum, which is in effect an exceedingly sensitive adaptation of the plumb line.

Since then measurements of this sort have been carried out by von Rebeur, Kortazzi, Hecker, Orloff and others. The experimental results are so obscured by accidental disturbances, however, that their interpretation is difficult, and the results of these various observers differ widely.

In recent years Professor T. C. Chamberlin has been much interested in the possible effect of the earth tides on the ocean tides, and he and Professor F. R. Moulton have for years been anxious to secure some definite data on the plasticity of the earth, on account of its vital bearing on questions of planetary evolution. It was through them that Professor Michelson became interested in the problem of measuring the elastic properties of the earth and designed the experiments which were conducted last autumn on the grounds of the Yerkes Observatory, at Williams Bay, Wisconsin. These experiments are described in full, with graphs and tables of observations, in the Journal of Geology and in the Astrophysical Journal, for March; 1914.

Professor Michelson's idea was to substitute a long horizontal water surface for a long: pendulum, and measure the changes of Ievel at its ends. There are many advantages in this arrangement. The length may be increased to any desired extent. The water column may be entirely under ground and thus, to a very large extent, freed from temperature disturbances. Earth tremors produce but little if any effect.

The arrangement actually used was as follows. An iron pipe, 500 feet long and 6 inches in diameter, was buried in a trench 6 feet deep along an accurately determined east and west line. At each end there was a pit 10 feet deep and 8 feet square, walled with concrete. The pipe was leveled, certainly to within one half inch, and probably to within one quarter of an inch, and half filled with water. A gauge at each end was connected at the top to the air space in the pipe, and at the bottom to the water. A needle point in each gauge was brought up from below until it nearly touched the surface of the water. The needle point was illuminated through a window in one side of the gauge by a small electric flash light. The under surface of the water formed a very perfect mirror, and the distance between the pointer and its totally reflected image was read, through a second window, with a micrometer microscope. Gauges, pipe and windows were all air-tight, so that fluctuations in barometric height at the ends were without effect. If the gauge at one end was open, the image at the other was not steady, but when both ends were closed, the reflected image was as steady and sharp as the pointer itself. Microscopes were used for which a millimeter at the focus corresponded to about 17 revolutions of the micrometer head. Observations were taken by measuring the distance between the pointer and its image at one end of the pipe, 
and subtracting the corresponding difference at the other end. As the water moved, e. g., toward the east end of the pipe, in response to the tidal forces, the difference $(E)$ at the east end increased, since the water was rising higher above the pointer, and the difference $(W)$ at the west end diminished as the water fell there. The difference $E-W$ therefore increased from hour to hour. When the water moved toward the west end of the pipe, the difference $(E)$ decreased and $(W)$ increased, and $E-W$ diminished. The values of $E-W$ plotted as ordinates against the time as abscissas, gave curves which represented the observed tides. Since the water moved down at one end and up at the other, and since the reflected images moved twice as far as the water surfaces, a fourfold magnification was secured. Moreover, since any change in level which might be caused by small changes in temperature or leaking altered the level at both ends alike, the errors caused by such disturbances disappeared in the double difference $E-W$. Changes in level due to the settling of the pipe between the ends were also without effect. If, however, one end settled more than the other, the double difference would increase or decrease, depending on whether the east or west end settled more rapidly, and the whole curve would be given an upward or downward slope. A similar effect would also occur if there were an appreciable change in the slope of the rock strata. But since such changes were not periodic, they would not affect the result seriously.

About eighteen or twenty readings per day, at intervals of from one to three or four hours, were taken during August, and it became evident that the method was capable of yielding very accurate results. A similar line was therefore installed in a N.-S. direction. During October and November readings were taken by the writer on both the N.-S. and E.-W. lines, with the assistance of Mr. Harold Alden, of the Yerkes Observatory staff. Readings were taken once an hour from 6 A.M. to 12 P.M. and once in two hours from 12 P.M. to 6 A.M. About four minutes usually elapsed between readings at one end of a line and the other. The mean time of the two was taken as the time of the observation. The result was the same as if the two ends had been read simultaneously at the mean time. The observations began at 8 A.M., September 27, and ended at 2 P.M., November 29, 1913.

The curves representing the tides in both the E.-W. and N.-S. pipes were very satisfactory. They showed with great faithfulness tides of the expected form, including the diurnal inequality, and spring and neap tides. The actual change of level at each end at spring tide amounted to about 0.001 inch.

But securing these observations was not all of the problem. It was necessary to know what the tides in the pipes would have been if the earth were absolutely rigid. Computations to determine them were made by Mr. W. L. Hart under the direction of Professor F. R. Moulton. The tidal forces acting on the water in the pipes depend on the positions of the sun and moon relative to the observer. These positions change in a very complicated manner. In the first place, the moon rises in the east and travels westward across the sky because of the earth's rotation. The moon has a motion eastward among the stars, completing a revolution around the earth in a month. Besides this eastward motion, it makes each month an excursion from $28^{\circ}$ (at the present time) north of the celestial equator to $28^{\circ}$ south of the celestial equator. Its distance from the earth varies by about 10 per cent. during the month, and its eastward motion among the stars is far from being uniform. In addition to all these things the attraction of the sun on the moon causes its motion to be more irregular than it would otherwise be, and it never moves around the earth twice in the same orbit. When all of these complex changes are properly compounded with the almost equally complex ones coming from the sun, the variations in the actual tidal forces are obtained.

Fortunately the Ephemeris gives us the positions and distances of the moon and sun for every hour, thus saving an enormous amount of computation. Even with this aid the work of computing the tides in the pipes 


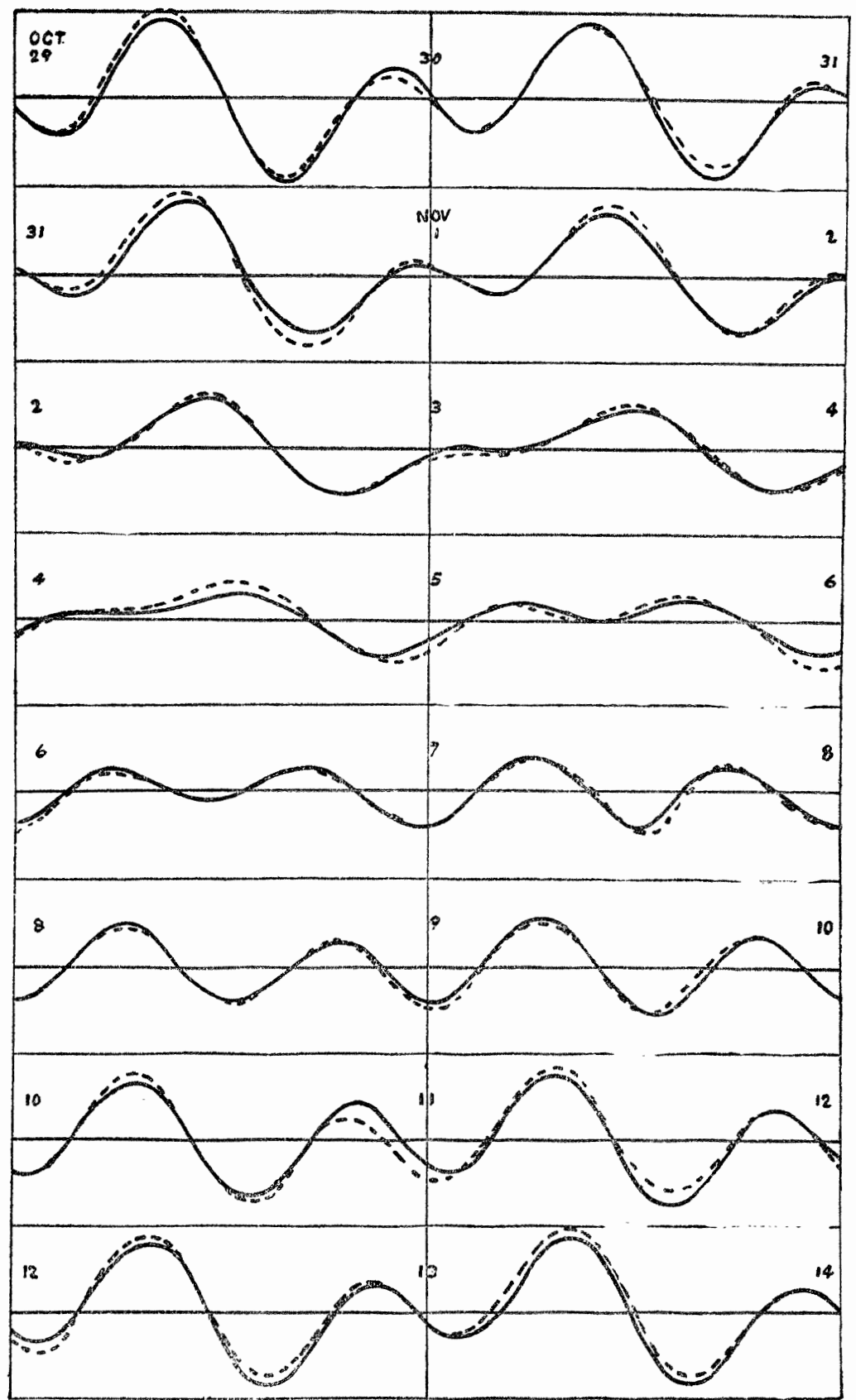

Fra. 1. E.-W. Dotted curve, observed values; full eurve, 0.7 of calculated.

was very great. As the experiment progressed and the order of accuracy in the observations was seen to be high, it became necessary to increase the rigor of the computations. It was found necessary, for example, to take account of the fact that the tidal force of the moon is greater on the side of the earth next to the moon than on the opposite side. This 


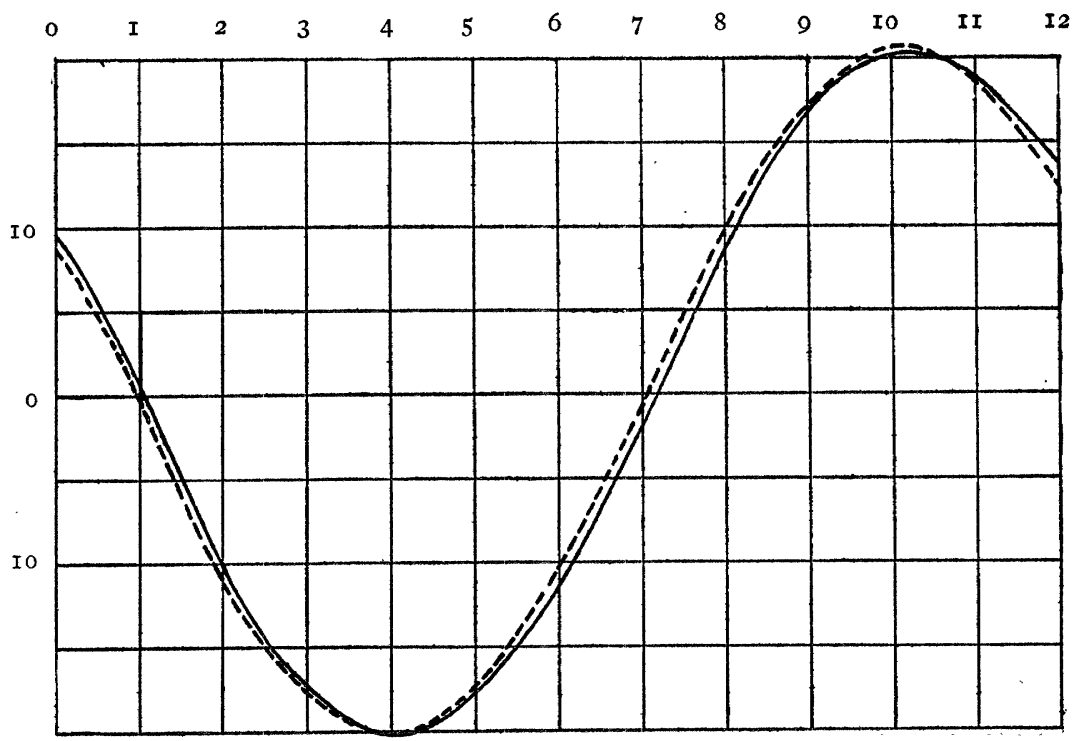

Fig. 2. E.-W. Mean of all observations, semi-daily lunar tide. Dotted curve, observed values; full curve, 0.7 of calculated.

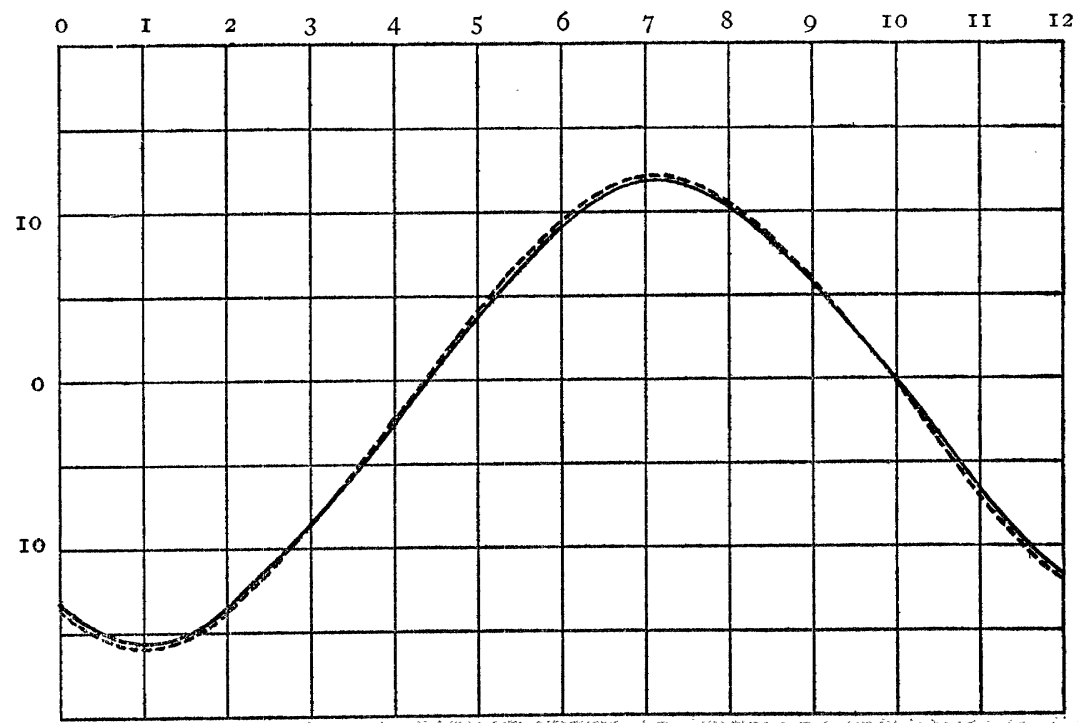

FIG. 3. N.-S. Mean of all observations, semi-daily lunar tide. Dotted curve, observed values; full curve, 0.5 of calculated.

refinement has not heretofore been necessary in work on the tides, but it introduces differences of as much as 3 per cent. In its final form Professor Moulton's formula, including harmonics of the third order, took account of all factors which affected the result by as much as 1 per cent., the probable accuracy of the experimental work.

In comparing the observed and computed tides in the E.-W. pipe, Professor Michelson found that if the computed tides were multiplied by the factor $7 / 10$ they agreed almost 
perfectly with the observed ones. But the computed tides for the N.-S. pipe had to be reduced to about one half of the computed values to give the best agreement with the observations. Sample curves for the E.-W. line are given in Fig. 1, and the final mean values of the semi-daily lunar tide for both lines are given in Figs. 2 and 3. The values of the ratios finally adopted were

$$
\begin{aligned}
& \text { E.-W. ............... } 0.710
\end{aligned}
$$

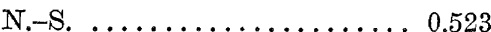

These figures mean that the water tide in the E.-W. pipe was only 71 per cent. of what it would have been if the earth were perfectly rigid, $i$. e., there is an E.-W. tide in the solid earth which is $290 / 710$ as large as the water tide. In a N.-S. direction there is an earth tide $477 / 523$ as great as the water tide. That is, the earth yields more readily to distorting forces in the N.-S. direction than in the E.-W. direction. Twice each day the surface of the solid earth rises and falls about a foot.

This result is rather surprising, as there appears to be no simple reason why the earth should be more rigid in an E.-W. than in an N.-S. direction. The result was, however, foreshadowed by Schweydar, in discussing the observations of Hecker at Potsdam. A. E. $\mathrm{H}$. Love has suggested that the effect may be due to the distortion caused by the weight of the ocean tides against the edges of the continents.

The times of high tides along the seacoasts with reference to the moon's position are of course very irregular, but if these enormous masses of water were flung against the coasts at the time they were due to rise in obedience to the moon's attraction, there can be little doubt that the effect would be to reduce appreciably the east and west earth tides, and thus to increase the apparent rigidity of the earth in this direction. But the ocean tides are so very complex that there appears to be little prospect of making accurate calculations on this point at present.

Added significance is given to the possibility that the ocean tides are responsible for the difference between the E.-W. and N.-S. rigidity by a consideration of the daily, instead of the semi-daily, tide. In reducing the observations Professor Michelson found that if he considered the tide of period 25.812 hours, instead of the semi-daily tide, the ratios of observed to computed amplitudes were

$$
\begin{aligned}
& \text { E. }-W . \ldots \ldots \ldots \ldots \ldots \ldots \ldots \ldots . .72 \\
& \text { N.-S. .............. } 0.66
\end{aligned}
$$

The agreement here is much better than for the semi-daily tides, but as Professor Michelson has said, if the Love-Schweydar theory is correct, we would have expected a considerable increase in the E.-W. ratio, when the disturbing effect of the ocean tides was eliminated.

Of no less importance than the ratio of the observed to the computed amplitudes is the question of their agreement in phase. It was found that the maxima and minima of the observed and computed tides occurred almost exactly simultaneously. The difference in phase furnishes a measure of the plasticity or viscosity of the earth. If there is no difference in phase between the observed and computed tides, the distortion of the earth does not lag behind the tidal forces; $i$. e., for any given value of the force the distortion does not tend to increase with the time. If there were a lag in the earth tide, it would throw the observed water tides ahead of the computed ones. This is rendered obvious at once by an appropriate graph. In the reduction of the observations, Professor Michelson found that the N.-S. tides were behind the computed ones, in the mean, by about 24 seconds. This lag could have no physical meaning, and the amount is well within the limits of observational error. In the E.-W. pipe the reduction shows an acceleration of 3.6 minutes. This may be a real acceleration, but the quantity is not far from the limit of accuracy of the observations, and it is too small to be regarded as highly accurate.

The agreement of phase between the observed and computed waves is of great importance for the theories of planetary evolution. Darwin's theory of planetary fission, $i$. e., the breaking off of the moon from the earth and its subsequent withdrawal to its present distance, is based on the assumption 
that tides exist in the solid masses, which are of a viscous and not an elastic character. If tides are raised in a viscous body the protuberances are carried past the line joining the centers of the bodies and the differential pull on the protuberances acts as a brake on the motions of the system. The resulting effect is to slow down the rate of rotation and increase the distance between the two bodies. The tidal theory of the evolution of the moon depends chiefly on the assumption that such tides exist in the earth. The results of this experiment show that the earth-moon system has not undergone the evolution supposed by Darwin unless the interior conditions were formerly vastly different from what they are at present.

Professor Moulton's calculations show that if the ratio of the observed to the calculated tides is taken as 0.70 and the acceleration of phase as the mean of the E.-W. and N.-S., $i$. e., 1.8 minutes, the mean rigidity of the earth is about $8.6 \times 10^{11}$, and the viscosity is $10.9 \times 10^{16}$, in C.G.S. units. These are of the order of magnitude of the rigidity and viscosity of steel. These calculations assume that the distortion decreases in geometrical progression as the time increases in arithmetical progression, and that the substance of the earth is homogeneous, a condition which does not, of course, exist. We may say, however, that the earth tides are approximately what they would be if the earth, through and through, had the properties of ordinary steel.

It would be a matter of very great interest to have similar series of observations taken at various places on the earth. Professor Chamberlin is very hopeful that the whole problem of ocean tides, now so intricate and apparently insolvable, may yield to investigations conducted along lines which take account of the joint action of the water tide and body tide. There can be no doubt, as he has pointed out, that the tides in many places are largely influenced by the rocking of the basins. It would be necessary to conduct a number of investigations like the one herein described in different regions to give definite knowledge of the facts as to the amount of the body tide, to- gether with an ample series of inspections of the basins of the great water bodies. Professor Chamberlin also believes that we should have further investigations of this kind on account of their bearing on vulcanism and seismic disturbances. These phenomena are almost certainly connected with the elastic state and degree of rigidity of the earth-body and of its different parts.

It is Professor Michelson's intention to install an automatic recording device, and to continue the observations at Yerkes Observatory by interference methods. A considerably higher degree of precision is expected.

Henry G. Gale

The University of Chicago

\section{EDUARD SUESS}

Eduard Suess, dean of modern geology and geologists, passed away on April 26, 1914, in the fullness of his eighty-three years, revered by all students of his chosen earth science and loved by all who came under the influence of his warm personality.

The son of a German merchant of Jewish extraction, Suess was born in London on August 20,1831 . Here his parents resided until 1834, when they removed to Prague, and eleven years later to Vienna, where the youth was destined to rise to great eminence in the university, in the council of the city, and in the Austrian parliament. Suess was born and lived in an environment that made of him a great linguist, and during a period of his life it is said that he acquired a new language each year. Certain it is that he was at home in many tongues; and more than once, on receiving one of his characteristic letters, has the writer noted the ease with which he expressed his thoughts in English.

While in the Polytechnic School, it became apparent that Suess's natural bent was wholly toward natural history studies, and at nineteen years of age he published his first paper, a short sketch of the geology of Carlsbad and its mineral waters. In 1851 he was appointed as assistant in the geological department of the Royal Natural History Museum at Vienna, where for the next eleven years he devoted 